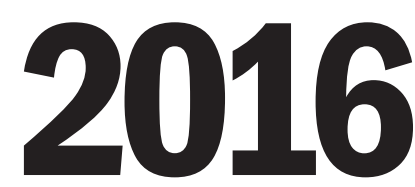

volume 13 | issue 1 an open access journal for architectural research

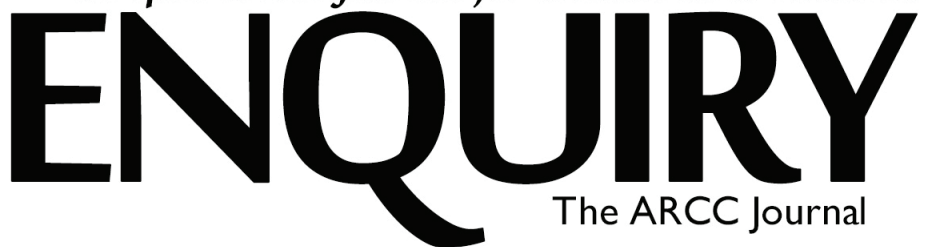

\title{
Resilience Theory and Praxis: a Critical Framework for Architecture
}

\author{
Michelle Laboy and David Fannon
}

\begin{abstract}
The growing use of resilience as a goal of architectural practice presents a new challenge in architects' responsibility for health, safety, welfare and poetic expression of human-building interaction. With roots in disaster response, resilience in the building industry emphasizes the preservation and rapid restoration of the physical environment's normal function in the face of shocks and disturbances of limited duration. The focus on maintaining function, and/or rapidly returning to the status quo ante necessarily affords a narrow understanding of architecture and a limited view of the concept of resilience. While useful at certain scales of time and inquiry, this so-called engineering resilience approach is only one among many within the broad discourse across diverse disciplines such as psychology, economics, and ecology. Drawing on the academic and professional literature of resilience outside the discipline, this paper explores the multiple competing frameworks represented; considers their influences and implications for architecture and the built environment at multiple scales; and examines the overlaps with existing discourse on change, architecture and time. The analysis of alternative concepts enables a critical perspective to move beyond the circumscribed, functionalist approach afforded by engineering resilience currently guiding architecture practice, towards a framework of social- ecological resilience that can fully embrace the richness of architecture, and results in a necessary and clear theoretical basis for the resilience of architecture over time in a climate of increasing uncertainty.
\end{abstract}

Permissions and copyright

Authors retain copyright and grant the journal right of first publication with the work simultaneously licensed under a Creative Commons Attribution License that allows others to share the work with an acknowledgement of the work's authorship and initial publication in this journal.

Attribution-NonCommercial-ShareAlike 4.0 International (CC BY-NC-SA 4.0)

You are free to: Share - copy and redistribute the material in any medium or format. Adapt - remix transform, and build upon the material for any purpose. You may not use the material for commercial purposes. The licensor cannot revoke these freedoms as long as you follow the license terms.

Under the following terms: Attribution - You must give appropriate credit, provide a link to the license and indicate if changes were made. You may do so in any reasonable manner, but not in any way that suggests the licensor endorses you or your use.

No additional restrictions - You may not apply legal terms or technological measures that legally restrict others from doing anything the license permits.

Hab 98 . Mlechelle and David Fannon. 2016. "Resilience Theory and Praxis: a Critical Framework for Architecture." Enquiry 13 (1): 39-52. Http://dx.doi.org/10.17831/enq:arcc.v13i2.405

\section{KEYWORDS}

Social-ecological, Resilience, Adaptability, Equilibrium, Time

\section{BACKGROUND}

The concept of resilience has been used as a conceptual framework in multiple disciplines to evaluate the ability or capacity of a person, object, entity, or system to persist in the face of disruptions or difficulty. The use of the term resilience in this context-as opposed to its original use describing an elastic material's ability to "spring back" or "rebound" after compression ("Resilience" 2016) - can be traced back to studies in Psychology and Ecology in the early 1970s (Holling 1973; Luthar, Cicchetti, and Becker 2000; Brand and Jax 2007). The term has since been adopted by, and adapted to, a diverse range of disciplines needing to define the different mechanisms to manage risks and vulnerabilities, and the capacity to absorb shocks, uncertainty and change through renewal, reorganization, and adaptation.

\subsection{Domains of Resilience}

The definitions and methods of evaluating resilience vary by discipline and event, and include quantitative and qualitative frameworks (Hosseini, Barker, and Ramirez-Marquez 2016). Researchers attempting to organize the multiple definitions and applications of the term have categorized four domains of resilience in human systems: technical, organizational, social and economic (TOSE) ( Bruneau et al. 2003; Tierney and Bruneau 2007). The technical domain refers to the physical attributes, and encompasses the vast majority of the designed world, including the built environment of infrastructure, buildings and designed landscapes. The organizational domain considers the governing institutions or managing structures that enact plans, policies, and regulatory frameworks to organize planning, mitigation, preparation, emergency response and reorganization of systems. The social domain considers the vulnerabilities and adaptive strengths of individuals and populations affected by a disturbance. The economic domain considers the capacity of local or regional economies, to prepare and respond by innovating, rebuilding and reorganizing. These domains encompass most categories of systems affecting the resilience of human beings and human environments to different kinds of disturbance. It is, however, a limited model because it does not explicitly include ecology, the natural world or the environment. 
Some authors include the natural environment in the social category (Hosseini, Barker, and Ramirez-Marquez 2016) but while human beings are part of ecosystems, many aspects of ecosystems are not products of human social structures, and this designation may neglect the physical properties of the natural world. Similarly, ecosystems may reflexively affect organizational structures, but are certainly not within that domain. Addressing ecosystems through the economic domain tends to view them solely as resources for extraction. And while human actions increasingly dominate the natural world, as suggested by the recent recommendation to name the current geologic epoch the Anthropocene (Crutzen, 2000; Carrington, 2016), the natural environment is not yet an intentional human artifact or entirely a product of human design, the way the technical domain clearly is. However, resilient human systems necessarily include and depend on natural systems and resources, which could otherwise constitute an ecological or environmental domain of resilience on their own. The TOSE model is primarily for assessment, and therefore it organizes different dimensions to measure the resilience of specific things, persons or communities to events external to them. However, if we consider the human environments as embedded and influential in ecologies, it is not possible to extract ourselves from the natural environment, which becomes a domain of the resilience of the entire system.

Based on a survey of recent scholarly literature, the disciplines of environmental science, ecology, and psychology have by far dominated the academic discourse on resilience, as evidenced by the number of peer-reviewed publications on the subject (Hosseini, Barker, and Ramirez-Marquez 2016). These disciplines have created conceptual frameworks for defining and evaluating resilience at multiple scales, from the level of a single individual or species to larger systems of communities or ecosystems. Hosseini, et al. (2016) used CiteSpace (Chen 2006) to visualize the literature related to resilience, which indicates that although the engineering discipline has a lesser proportion of publications, it is still the largest representation of the fields engaged in the built environment. It is important to note that resilience within the engineering domain is often focused on hazard mitigation which is discussed in depth later in this article. Notably, the disciplines of urban studies and planning produce a small but growing number of publications on resilience. Moving to the broader discourse and analyzing the use of the word resilience in the published literature, as illustrated on Figure 1, shows that the use of the term urban resilience has increased exponentially since 2001. Other terms related to the resilience of the built environment, including resilient city and resilient infrastructure follow similar patterns. ${ }^{1}$

\footnotetext{
${ }^{1}$ The term resilient city was used sporadically before the 1970 s, referring mostly to the character of a specific population. Similarly the early use of the term urban resilience emerged in the 1980 s to refer mostly to communities of low income, but its increased use coincides with a focus on resilience to natural disasters, climate change and terrorism. Likewise, the term resilient infrastructure appeared in the 1970s, but increased dramatically in the last two decades. However, the term resilient architecture, which also follows similar patterns, has been used almost exclusively to refer to software or computer networks, suggesting architects have not only been absent from the academic literature about resilience, but also have relinquished the term architecture to other fields (Google, 2016).
}

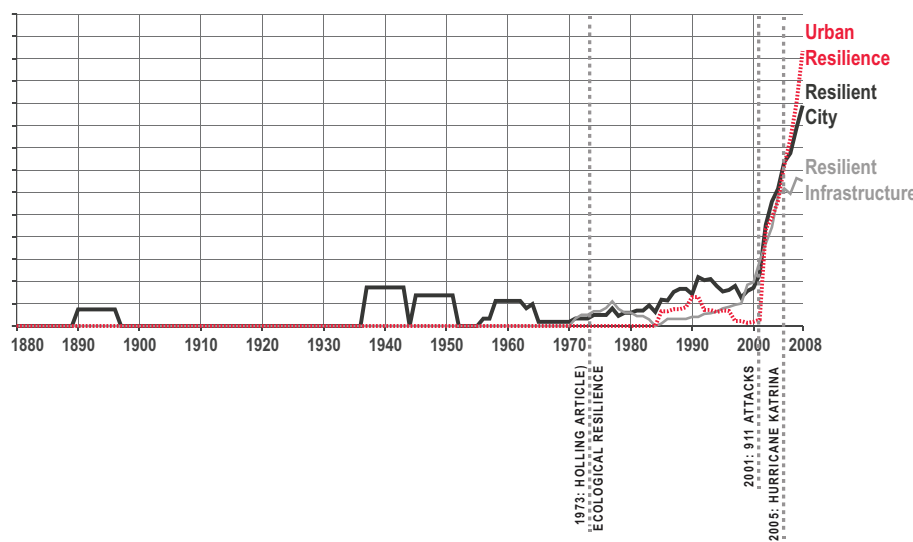

Figure 1. Use of the term urban resilience, resilient city and resilient infrastructure in the literature over time. Adapted from Google Books Ngram viewer. (Google 2016)

The pattern of use of these terms aligns with the timing of significant events, including the terrorist attacks of September 11th, 2001 in New York City, the Indian ocean earthquake and tsunami of 2004, and Hurricane Katrina on the gulf coast of the United States in 2005; and it continues to increase with more recent events, including the triple disaster following the Tohoku earthquake off Japan in 2011, and Hurricane Sandy in the east coast of the United States in 2012, among others. These recent large-scale natural and manmade disasters have clearly demonstrated the limitations of conventional risk management in the built environment, and of course, the complex web of technical, social, economic and organizational domains. As in all aspects of life, risk is inherent in the design, construction and operation of the built environment, hence long-standing efforts sought to systematically assess, manage, and ultimately protect against risk, commonly understood as the combination of uncertainty and potential harm (hazard) (Hosseini, Barker, and Ramirez-Marquez 2016). However, these events demonstrate that not all undesirable events or their effects can be predicted, much less prevented, leading to growing interest in the term resilience to characterize the response to inevitable (but perhaps unknown) disruptions (Kaplan and Garrick 1981).

\subsection{Reactionary Resilience}

In the wake of recent disturbances, the American government partnered with various organizations in efforts to define, evaluate and build resilience (Executive Office of the President, Council on Environmental Quality 2015). A 2013 directive from President Obama defined resilience as "the ability to anticipate, prepare for, and adapt to changing conditions and withstand, respond to, and recover rapidly from disruptions." The Rockefeller Foundation (2016) adopts a slightly broader view, defining resilience as "the capacity of individuals, communities and systems to survive, adapt, and grow in the face of stress and shocks, and even transform when conditions require it." To engage the design community, the Rockefeller Foundation partnered with the government and many other organizations in 2013 to fund a major design competition called "Rebuild by Design" that selected 10 international teams of renowned design firms to design ecologically resilient strategies for areas in the 
Northeast affected by Hurricane Sandy ("Rebuild by Design" www. rebuildbydesign.org). These projects primarily speculated how restoring ecological systems in the urban landscape would improve the adaptive capacity of cities.

Operating mostly outside of academia, practitioners and NGOs sought to articulate general principles for resilience in the built environment. ${ }^{2}$ Furthermore, assessments or rating systems specific to resilience have also emerged in the industry. ${ }^{3}$ Public incentive programs provide evaluations and guidance as well as funding upgrades for homeowners to prepare for specific events ("My Safe Florida Home Hurricane Inspection Info" 2016). Foundations and NGOs are also active. The Rockefeller Foundation promotes resiliency efforts globally by funding resilience plans for cities, (Rockefeller Foundation 2016) while FLASH publishes practical guides ("Resilient Design Guide: High Wind WoodFrame Construction Edition" 2015) for construction and advocates changes to the building code (Chapman-Henderson and Rierson 2015). Such updates are discussed in congressional testimony and were the subject of a recent White House conference (White House Conference on Resilient Building Codes 2016). While useful, timely and relevant, these efforts tend to be narrowly drawn and technically focused, rather than comprehensive and conceptually driven.

Central among all these efforts in the United States is the Building Industry Statement on Resilience, first released in May 2014, by a group of twenty design and construction industry associations convened by the American Institute of Architects (AIA) and the National Institute of Buildings Sciences and calling itself "The Alliance for a Resilient Tomorrow." The statement echoes the National Research Council, defining resilience as "the ability to prepare and plan for, absorb, recover from, and more successfully adapt to adverse events" and provided a framework for industry and public efforts in research, education, advocacy, and preparedness related to the built environment. The group has since expanded to some forty signatories, recast as the "Resilience Building Coalition," and claims to represent the position of nearly 1.7 million workers, and over \$1 trillion of GDP that make up the design and construction industry in the United States, establishing it as the connection among the various resilience efforts in the professional sphere. In a 2016 update, the group reports on progress since the initial statement, and the growing slate of activities and initiatives undertaken by signatories (Resilience Building Coalition 2016).

These significant efforts are reactions based on the experience and observation of specific extreme events in the recent past. This

\footnotetext{
${ }^{2}$ These have been informally published online by non-profit organizations of professional planners, architects, engineers and environmental consultants ("ResilientCity | Resilient Design Principles" 2016; "ResilientCity | Resilient Design Principles" 2016; “Resilient Design Strategies" 2016)

${ }^{3}$ These metrics are often building type or event specific and modeled on sustainability or energy efficiency rating systems, including Fortified Home (Insurance Institute for Business and Home Safety 2016) , US Resiliency Council (USRC) Earthquake Building Rating System("Building Rating Systems - USRC" 2016), Resilience-based Earthquake Design Initiative (REDiTM) by Arup (Almufti and Willford 2013). Some specifically identify how existing sustainability credits are related to or likely to have an effect on climate adaptation, such as the LEED Resilience Pilot Credits(“LEED Credit Library | U.S. Green Building Council” 2016).
}

responsive-or perhaps reactionary-approach to resilience risks a "lock-in" scenario in which solutions are modeled on recent events. In that scenario social conditions, practices, rules, and laws develop "path dependence" that preserve existing structures and encourage a slow-down in restructuring (Pendall, Foster, and Cowell 2010). The notion of path dependence is particularly relevant to urban centers, given the inherent inertia of the built environment and everything from land ownership to regulatory structures and construction practices. The danger of a locked-in pathway is that "only a massive or radical shock or stress is enough to motivate path-breaking behaviors and changes" (Pendall, Foster, and Cowell 2010), precisely the type of danger made evident in cities impacted by recent events. Wu and Wu (2013) warn that a design focus on building "specified resilience" to particular events, as opposed to "general resilience" to the unknown or unpredictable, is likely to lead to a focus on mitigation, resistance and risk management of specific places for predictable events based on observed experience in the short term. Ironically, the specified approach is in a way simply another form of fragile optimization, in contrast with the more sustainable approach of dynamic, adaptive management of the unpredictable in the long term. A more critical framework can help build general resilience and avoid path dependency by focusing on uncertainty and unpredictability.

\subsection{Islands of Resilient Architecture}

After evaluating the extensive multidisciplinary literature, researchers in regional dynamics have convincingly argued that the concept of resilience is helpful as a metaphor for understanding change at a regional scale, for example the complexity and system dependencies of the urban environment. Cities need to be resilient, and we must look at them holistically as well as their component parts. For example, buildings constitute a large component of the physical, social and cultural life of the city, and the discipline of architecture must critically consider the meaning of resilience for buildings. However, because buildings are such vital parts of the city it is unlikely buildings should be considered in isolation from their urban contexts, lest they become what Stephen Flynn characterizes as islands of resilience awash in a sea of fragility. ${ }^{4}$ His metaphor illustrates that buildings and its users are connected to systems at multiple scales in complex ways that make focusing solely on resilience at the building scale insufficient and often, ineffective. It is worth considering that if architecture were limited to the scale and scope of buildings, resilience in architecture would be a purely technical or infrastructural problem, and all other domains of resilience would presumably occur at the scale of the individual person or at the urban scale. However, architecture is not mere building, and what distinguishes architecture from buildings is its cultural value and the intentionality, often expressed through theory and evaluated through cultural criticism, to connect to the social and ecological life of the city.

Curiously, and in spite of having professional architects and architecture organizations in leadership, the industry-wide focus of the Resilience Building Coalition necessarily obscures the implications for architecture

\footnotetext{
${ }^{4}$ Steve Flynn, an international expert on critical infrastructure resilience and government advisor, made this comment in a guest lecture in the authors' architecture seminar, and has used it in other conversations as well.
} 
as anything beyond mere building. Thus while the professional discourse in architecture has taken up this term and idea of resilience (Minnery and FAIA 2015), it has done so without creating a clear, disciplinary-specific definition, or explicitly adopting any one definition from other disciplines ("Understanding Resilience" 2016). Curiously, the AIA locates the topic of resilience under the broad arc of its Sustainability Initiatives ("Resilience - The American Institute of Architects" 2016). Resilience is undeniably critical to any definition of sustainability (Walker and Salt 2012; Blewitt and Tilbury 2013), but the conflation of terms obfuscates, contributing to a narrow focus on climate change and resistance to natural disasters. For example, the AIA provides members a "Framework for Resilience" which focuses on disaster mitigation, response and recovery, including a section titled "The Architect + the Disaster Cycle" and only briefly mentions the term adaptation, without touching on how that affects practice, or indeed relates to sustainability ("Framework for Resilience" 2016). Absent a clear conceptual framework, an uncritical approach to resilience risks devolving into metaphor, and worse, not elucidating the fundamental implications of design for variability, uncertainty, and risk for a discipline that has been traditionally defined by notions of stability and permanence.

As shown so far, the discourse on resilience of the built environment has been essentially practice-driven and reactionary, generated in response to recent events that caused severe disruptions in urban life, including natural disasters, terrorism, and economic recessions, which made vulnerabilities of the physical infrastructure visible and demanded reconstruction. Such disturbances are expected to increase in frequency and severity as the population of the world becomes more urban, climate change accelerates, and political and economic crises unfold, yet focusing on these risks locks the built environment into a fragile, specified approach. An alternative to such path dependence is to dive deep into the definitions and implications of resilience to elucidate ways adaptive strategies can derive from leveraging existing conceptual frameworks in a climate of uncertainty. As an initial attempt in this direction, this article examines these concepts of resilience in the context of architectural theory and praxis

\section{FRAMEWORKS FOR RESILIENCE}

The state of resilience in the building industry militates for a closer examination of the frameworks, assumptions and intellectual structures under which it operates. This section draws on the resilience literature outside the building industry to articulate structures helpful in establishing a conceptual theory of resilience in architecture. The history of the study of resilience, as well as the diversity of disciplines engaged in it have yielded a number of definitions, models and organizational structures (Hosseini, Barker, and Ramirez-Marquez 2016), including some mentioned previously. Perhaps the most fundamental divide lies in identifying which elements of a system are stable, and which are not: a topic first explored when Holling (1973) applied the idea of resilience to the field of ecology in the early 1970s. Based on our review of the external resilience literature, we identified three overarching frameworks for resilience in the built environment that, while accommodating individual variation, provide a useful taxonomy for resilience in architecture.
Figure 2 illustrates three broad frameworks using a metaphor in which a ball (representing the system) rests on a contoured surface (representing the context) in which cups or valleys in that surface represent stable equilibrium domains. Perturbing the system (i.e. moving the ball) can result in various behaviors depending on the nature of both the ball (system) and surface (context.) Engineering resilience concerns itself with the depth and steepness of the valley's sides, measuring return time, or how quickly the ball rolls back down to the previous equilibrium. Ecological resilience takes a slightly wider view, considering that a system sufficiently disturbed may "flip over" into a new stability regime (the ball rolls into a different valley) and so concerns itself with the magnitude of disturbance (distance) before entering a new equilibrium. In both those frameworks, the system is the only moving component, and the context is held to be fixed. Social-ecological or adaptive resilience, on the other hand, recognizes and attempts to address the consequences of changing contexts (surface shape) and systems (not only ball position but also size or center of mass) on system stability. It makes clear that even an unperturbed system is not stable if the context changes around it.

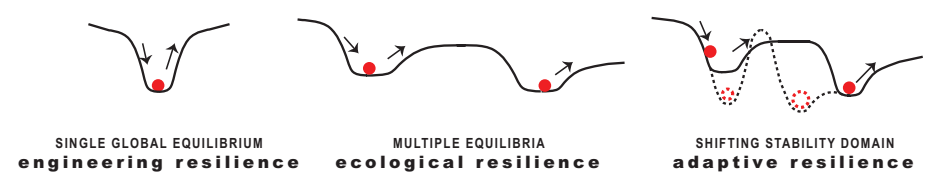

Figure 2: Ball and cup model of system stability in competing resilience frameworks. The valleys in the surface represent equilibrium or stability domains, the ball represents the system, and arrows represent disturbances. Adapted from Gunderson (2000) and Scheffer (1993).

Table 1 itemizes different characteristics, foci and contexts of these three primary resilience frameworks. Gunderson summarizes these differences quite succinctly saying, "Resilience in engineering systems is defined as a return time to a single, global equilibrium. Resilience in ecological systems is the amount of disturbance that a system can absorb without changing stability domains. Adaptive capacity is described as system robustness to changes in resilience" (Gunderson 2000). The social-ecological model makes a fundamental distinction from the engineering and ecological models: unlike natural ecological systems, the adaptive capacity of a physical system is determined in large part by social actors with or without intentionality (Walker et al. 2004). These frameworks are detailed in the following sections, including their dimensions, limitations, and possible application to architecture.

\subsection{Engineering Resilience Dimensions of engineering resilience}

Resilience of the built environment is often focused on the technical domain, with only modest attention paid to the interaction of other areas. This technical focus is perhaps best understood by the four R model (4R) proposed by Bruneau et al. (2003), which identifies robustness, redundancy, resourcefulness and rapidity as properties of technical and social resilience. Robustness is the strength of systems and elements to withstand or resist stress. Redundancy is the spare or excess capacity that enables continued function should one or more elements or systems fail, these are both the end goals and states of a resilient system. On the other hand, resourcefulness describes an organizational 


\begin{tabular}{llll}
\hline Framework & Characteristics & Focus on & Context \\
\hline Engineering Resilience & $\begin{array}{l}\text { Return time. Resistance, } \\
\text { Efficiency, Optimization }\end{array}$ & $\begin{array}{l}\text { Constancy, Stability, Robustness, } \\
\text { Rapidity }\end{array}$ & Vicinity of a stable equilibrium \\
$\begin{array}{l}\text { Ecological Resilience, Social } \\
\text { Resilience }\end{array}$ & $\begin{array}{l}\text { Buffer capacity, Maintenance } \\
\text { function, Latitude }\end{array}$ & $\begin{array}{l}\text { Persistence, Redundancy, } \\
\text { Resourcefulness }\end{array}$ & Multiple equilibrium states \\
$\begin{array}{l}\text { Adaptive or Social-ecological } \\
\text { Resilience }\end{array}$ & $\begin{array}{l}\text { Interplay of disturbance and } \\
\text { reorganization, intent }\end{array}$ & $\begin{array}{l}\text { Adaptability, Transformability, } \\
\text { Learning, Recovery }\end{array}$ & $\begin{array}{l}\text { Panarchy, dynamic stability } \\
\text { landscapes, multiple scales }\end{array}$ \\
\hline
\end{tabular}

capacity to detect problems and respond to them, while rapidity identifies the speed with which responses can occur to either limit or recover from a shock, both means by which resilience is accomplished. In prior work, the authors adapted the existing model to incorporate critical decision-making relevant to architecture by expanding the existing four-R model to a six-R model that includes "Risk avoidance" and "Recovery" (Laboy and Fannon 2015), as illustrated in Figure 3.

As a design discipline, architecture can help with avoiding risk in the first place, through site selection or reconfiguration for example. This early planning and adaptation step encourages us to shape our built environment to the realities of the environmental forces we understand and face. Similarly, the recovery phase proposed after rapidity focuses on future adaptation not merely to limit vulnerabilities by learning from prior mistakes but also to retool to current and future needs. In socialecological systems this has been described as "moving the threshold away," "moving away from the threshold," or "making the threshold more difficult to reach," all of which require social actors (Walker et al. 2004). The development of frameworks for artificial intelligence for adaptable building systems, which are "limited to the scale of the building and its users and not the urban form" (Keenan 2014) can be placed in an expanded model of recovery within the engineering realm. The social management of cross-scale interactions to avoid loss of resilience, or altering panarchy (Walker et al. 2004), necessarily engages multiple scales and moves engineering resilience towards a social-ecological model. This expanded model for engineering resilience extends the involvement of architects in shaping pre-planning and postoccupancy activities.

\section{Limitations of Engineering Model: Time to function}

Bruneau et al. (2003) defined the so-called resilience triangle model, a static-deterministic measure based on the notion of time to return to normal function. In Figure 2 the shape of the cup in a stability domain illustrates this view: the steeper sides suggest a faster return to the same condition. While seminal and useful, like all event-driven models this is a stability-focused model; predicated on design conditions after the event identical to (or closely resembling) the conditions before it. It also assumes that the building or system ideally remains more or less constant throughout, and that the identical shocks yield identical responses. None of these are necessarily true. While systems may return to normal after temporary shocks or predictable events, during unexpected disturbances of greater magnitude, and/or over longer time scales, the "normal" static context no longer exists, and the system must jump to a new normal, as illustrated in Figure 4 . The same
Table 1: Comparison of resilience frameworks adapted from Folke (2006) and Blewitt and Tilbury (2013).

behavior appears in natural systems, and Gunderson (2000) identifies several reasons for this, stating: "One reason why rigid scientific and technological approaches fail is because they presume a system near equilibrium and a constancy of relationships." (433) However, it is not just equilibrium that is a problem, the inherent complexity of relationships within systems may not be understood, or may difficult to model, as Gunderson notes "Scientific disciplines tend to break the management issue into parts for analysis, and have historically generated piecemeal sets of policies as solution." $(2000,433)$ The same is true in the built environment, where lack of interoperability and integration of diverse disciplines means engineered resilience can produce local optimization and global fragility.

\subsection{Ecological Resilience} Multiple equilibrium states and cross-scale interactions

In Figure 2, the ecological resilience model demonstrates system states that are far-from a single equilibrium and so the system can flip from one local equilibrium to another. In contrast to the engineering

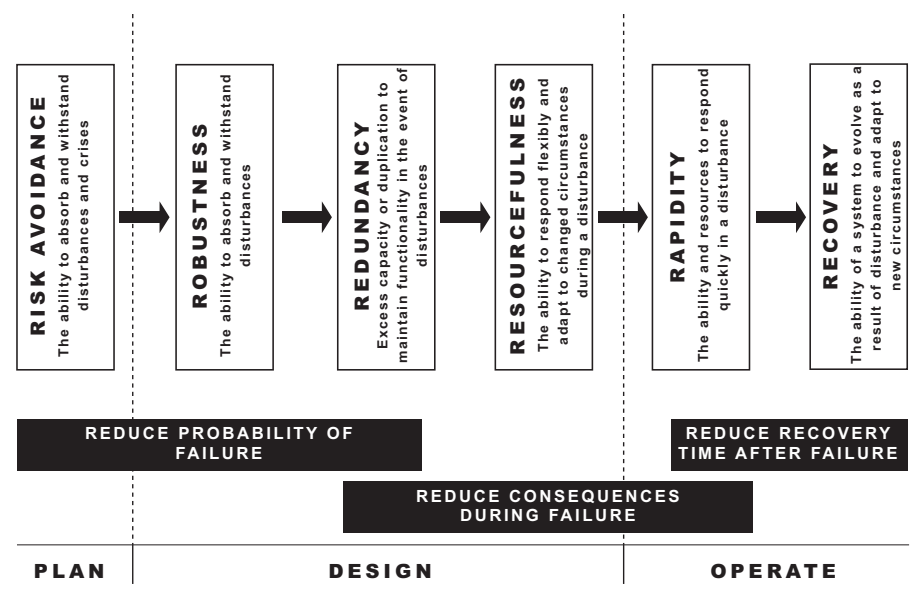

Figure 3. $6 \mathrm{R}$ model of dimensions of engineering resilience. The application of the $4 R$ model as adapted to the phases of architecture practice considers early planning decisions and late recovery and reorganization strategies. Image by the authors. 
measurement of time to function, ecological resilience measures the width of the stability domain (how far away can it get before it flips into the cup of a new stability regime).

Ecological resilience was first articulated for natural systems by ecologist C.S. Holling (1973) who distinguished stability, namely the "ability of a system to return to an equilibrium state after a temporary disturbance," from resilience, which provides "a measure of the persistence of systems and of their ability to absorb change and disturbance and still maintain

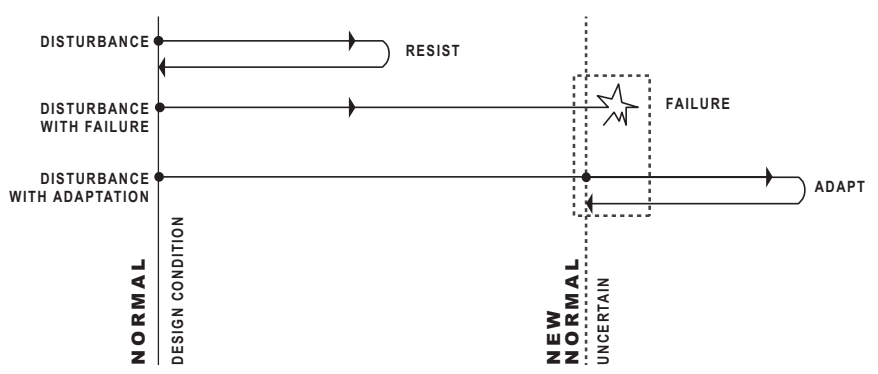

Figure 4. Disturbance and resilience in engineering and ecological frameworks. The engineering model sees either a return to an original condition (stability) or failure, whereas an adaptive model does not expect a return to the original condition or failure, but should adapt to a new normal. Image by authors.

the same relationships." (14) Where engineering resilience is associated with the functional stability expected from technological systems, ecological resilience is characteristic of complex and dynamic living systems. More than terminology is at stake here: optimization enhances the efficiency of the built environment, but solutions too precisely suited to the immediate need are also vulnerable to changing social and environmental contexts. Cities are embedded in coupled social and ecological systems, which are "sufficiently complex that our knowledge of them, and our ability to predict their future dynamics, will never be complete" (Berkes 2007, 284). Given the joint challenge of optimizing over the short term, and evolving over the longer, the ecological resilience model presented by Holling (1973) offers a useful shift in emphasis for buildings "from the equilibrium states to the conditions for persistence"(2). The last century proved architecture neither stable nor resilient, washed by tides of ecological deterioration, cultural devaluation and disinvestment. Holling might describe this current situation as the "interplay of stabilizing and destabilizing properties", between "two contrasting aspects of stability," namely "maintaining efficiency of function (engineering resilience)" and "maintaining existence of function (ecological resilience)" $(1996,54)$.

Although the ecological model is process driven for an ecosystem, consisting of cycles of colonization, maturity, collapse and re-growth, what is interesting to architecture is the notion of the nested scales. The use of the term resilient to describe cities-which like ecosystems are complex, dynamic, interconnected environments-acknowledges that cities are constantly changing yet increasingly vulnerable. It is important that, in this context, ecological conveys the focus on relationships among components and to their surroundings, but does not necessarily imply environmentalism or green design. Wu and $\mathrm{Wu}$ (2013) proposed ecological theories of urban design that view cities as panarchies, suggesting that the application of these views in urban design result in design principles that are different than traditional principles emphasizing stability, optimality and efficiency. Holling and others coined the term panarchies, the opposite of hierarchy, to describe systems nested across physical and time scales in which components are interconnected and none is more important than others. Panarchy suggests that the cross-scale interactions of a system will depend on the influences from states and dynamics at scales above and below (Walker et al. 2004).

We propose that the TOSE framework (Bruneau et al. 2003) helps explain the multifarious entanglement of architecture across scales. For clarity, placing the building in the center of the TOSE diagram in Figure 5 illustrates systems at the intersection of all four domains and allows the consideration that everything from building components to cities and regions interacts across physical scales, albeit in a more web-like form. While the technical domain of buildings is most prominently in the realm of conventional architecture practice, a critical discourse on resilience must understand and engage with all four domains at multiple scales.

\section{Limitations of the Ecological Model}

Applying resilience to the domain of infrastructure and the built environment initially drew from the extensive field of risk management, situating risk as a component within the larger concept of resilience. The National Institute of Building Science summarizes this scalar relationship, noting, "Hazard mitigation is at the core of disaster resistance and supports achieving resilience,"(WBDG Secure/Safe Committee 2016) but fails to interrogate the implications of a hazard and disaster focus. Because quantitative methods of risk management and disaster preparedness necessarily focus on specific events, their aftermath and what steps might prevent them, resilience in the built environment has tended to focus on acute rather than chronic conditions. This focus is made clear by the terminology of "shocks" and "events" which are by definition sharp, but short disruptions, a limitation organizations like the Rockefeller Foundation seek to overcome by including terms like "stresses" to describe longer-term and slower-moving challenges (2016). Even adaptation activities like preparedness and learning tend to organize around particular critical moments. Seismic design, for example, offers a model of learning after each event, a model expanded and systematized by the Federal Emergency Management Agency (FEMA) Mitigation Assessment Team program ("Mitigation Assessment Team Program | FEMA.gov" 2016). Yet all the focus on preparation before, recovery and learning after only serves to emphasize the primacy of a single event and the return to "normal" function. The Whole Building design guide claims that "Only after the overall risk is fully understood should mitigation measures be identified, prioritized, and implemented,"(WBDG Secure/ Safe Committee 2016) failing to acknowledge that in a dynamic world, such full understanding may be impossible, and any response hopelessly specialized.

The event-focus is not necessarily a return to status quo ante, the Building 


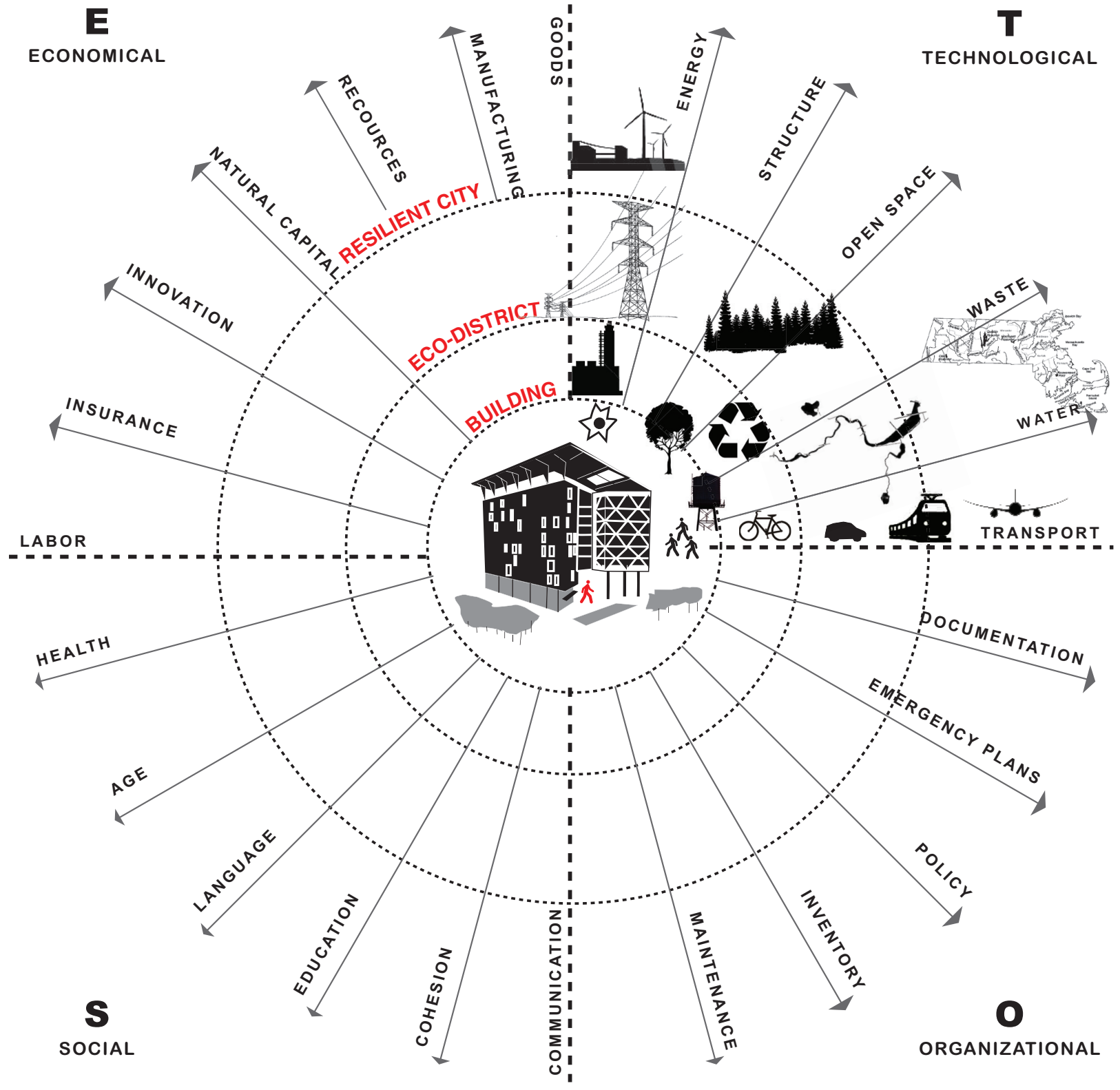

Figure 5. TOSE model for resilience in architecture. A model of ecological resilience suggests that buildings interact in nested scales below and above the artifact of the building in technical-ecological, economic, social and organizational domains. Image by authors.

Industry Statement on Resilience pledges to "help communities rebuild better and stronger than before," suggesting a recognition of a changed context, and perhaps a transition to a new stability regime, which is characteristic of ecological resilience. In a recent paper, Mannakkara and Wilkinson explored the history of the term "build back better" and the implications of this idea, ultimately calling for a reconceptualization, in part because it remains equilibrium focused (2014). They further note that both repair and restoration to the pre-shock state recreate identical vulnerabilities, ${ }^{5}$ and perhaps miss an opportunity during the reconstruction period (Lewis 2003; Among others, see Kijewski-Correa and Taflanidis 2011; Mitchell 1999). This suggests the importance of agency in the discussion about resilience. 


\subsection{Social-ecological (Adaptive) Resilience}

In Figure 2, the adaptive model of resilience recognizes that the stability domain itself is shifting (and, in an imperfect extension of the metaphor, the marble may simultaneously change size or center of mass also). The framework of social-ecological resilience assumes that the constructed and the natural environment have intrinsic qualities of engineering and ecological resilience (latitude, resistance, precariousness, panarchy) as well as transformability but the adaptive capacity lies in the social domain, with the actors that will organize and order the transformation of the system (Walker et al. 2004). Similarly, in discussing adaptability of buildings to climate change, Keenan argues, "the adaptation of buildings represents a duality of material (i.e. object) and social construction (managers/users)" $(2014,20)$. If architects are to be essential social actors organizing the transformation of the built environment, socialecological resilience is an important conceptual framework for the discourse, and a good model for the interplay between the technical, ecological and social domains.

Many definitions of resilience employ the term adaptation to overcome the inherent limitations of static approaches. Even the Building Industry Statement on Resilience makes gestures in this direction, noting "Our practices must continue to change, and we commit ourselves to the creation of new practices in order to break the cycle of destruction and rebuilding" (Resilience Building Coalition 2016). Unfortunately, that cycle is inherent in any approach that seeks at its core to prevent, resist, and counter change: such systems can be brittle in the face of a variable and unpredictable world. Thus, translating resilience into architecture requires that we think critically about the interplay between resilience qualities in short as well as long time frames. In the short-term, the important qualities include resistance (i.e. robustness, redundancy, durability) and reduced precariousness, a measure of how close a system is to a threshold. In the long term the critical qualities are the learning capacity of social actors coupled with the transformability of technical components, and latitude, a measure of the amount of change a system can tolerate.

Figure 6 organizes the three frameworks for resilience in terms of both resilience to short-term disturbances on the vertical axis (similar to "moving the ball" in Figure 2) and resilience in the face of changing contexts over the long-term on the horizontal axis (analogous to "changing the surface" in Figure 2). This arrangement and illustrated building types highlight particularly architectural characteristics of each framework. The suburban office typifies the status quo: a car-centric and energy-intensive siting and configuration, optimized for least-first cost and a particular model of work, that is both fragile in the face of disturbances and ill-suited to long term changes in cultural, economic, and ecological contexts. Engineering resilience yields buildings with the durability, robustness and redundancy to resist particular hazards such as earthquakes, major storms or bomb blasts, but such designs tend to be optimized to particular threats of expected magnitude, and their technical strength can prove brittle when situations or human needs change. Mill buildings, as an example of ecological resilience,

\footnotetext{
${ }^{5}$ Among others, see Lyons 2009; Kennedy et al. 2008.
}

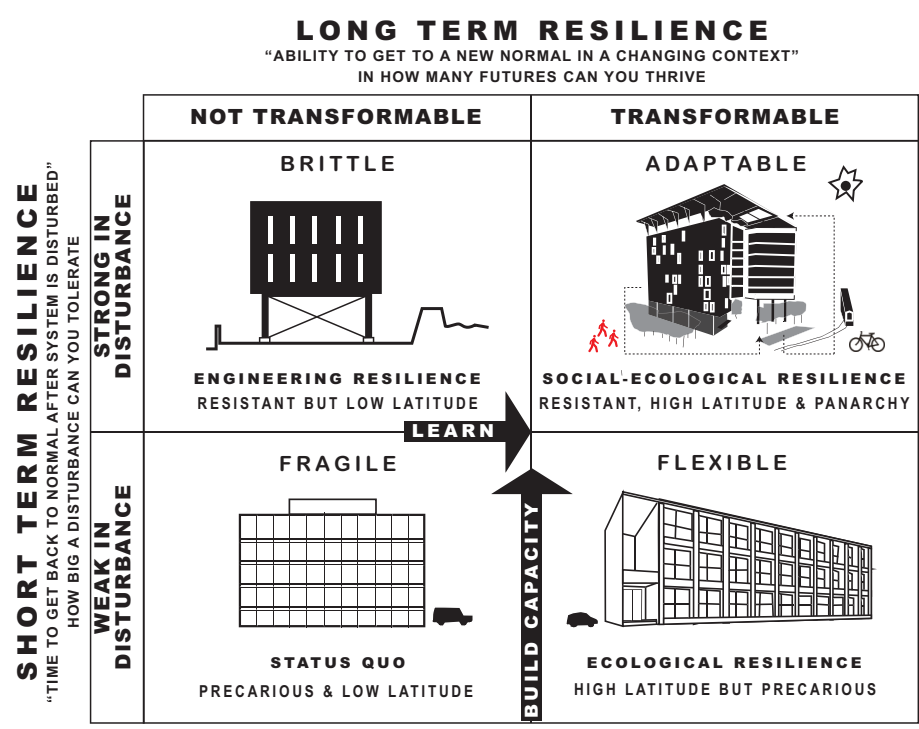

Figure 6. Adaptive resilience attributes. The adaptive capacity of architecture must consider both short-term, event-focused resilience and long-term transformability and adaptability. Social-ecological resilience involves both the physical capacity to resist short-term disruptions, and the built-in social capacity for adaptation in the longterm. Image by authors.

thrive in many contexts thanks to their spatial flexibility, durable massive perimeter, structural robustness, and abundant daylight, but historic industrial buildings tend to be located and constructed in ways that make them vulnerable to short-term threats. Many also sat abandoned for years before the changing urban context encouraged finding their useful second and third lives, suggesting that high-latitude does not preclude a period of uncertainty and disruption associated with seeking equilibrium in a new normal. The adaptable building incorporates both technical transformability and social resilience. Recognizing that adaptability is a social as well as technical construct, our ongoing research seeks to identify case-study buildings that foster these attributes. Although the transformation of building use over time is certainly a valid and central concern of architecture (Grabow and Spreckelmeyer 2015) there are many other aspects of adaptive resilience, some effort towards which will be described in the third section of this essay.

Gunderson (2000) articulates two key attributes of adaptive management in ecosystems, which are quite relevant for architecture. First, adaptive processes include learning, not merely the inherent lessons drawn from trial-and-error, but deliberate, considered reflection on choices and their consequences. In adaptive terms, learning enables long-term resilience in a dynamic world. Second, and equally important, adaptive systems generate novelty, as Gunderson notes, "A unique property of human systems in response to uncertainty is the generation of novelty. Novelty is key to dealing with surprises or crises." $(2000,434)$ In both natural and human systems, novelty is critical to enhance capacity with new approaches, and in this way can not only build robustness, redundancy or resistance to shocks and disruptions but also organize and enable future learning. Ecosystems left to themselves create 
novelty only on the slow scale of mutation and evolution over millennia including many mutations that do not survive. On the other hand, human-involved systems uniquely produce novelty over much shorter time scales, although with equal or perhaps greater risk of unfitness, for example by glorifying the new for its own sake. The ability to build capacity through novelty, and to enhance long-term resilience through learning are essential to building resilience, as depicted in Figure 6.

For all the mathematical tractability and comfortable stability of a near-equilibrium approach, and in spite of the complex uncertainties of multiple-equilibrium ecological models: the creative opportunity presented by the variability of buildings and their contexts can only be fully realized in an adaptive model of practice. This model not only adapts to change but anticipates, accepts, and celebrates it. The approach also recognizes the reflexive influence of our intentions towards the built environment as literally constructing a new normal, which implies an expectation of a new period of stability. It is in this state of perpetually dynamic-rather than multiple-equilibrium states, in which the use and significance of buildings may endure and perhaps flourish; not in spite of but rather because of a changing context.

The critical call for the discipline of architecture is to intend to learn, plan, and create in ways that enable adaptation in the long-term; and that call also includes defining acceptable thresholds of change and forms of resistance that enable a culturally desired stability in the shortterm. As Brand (1994) notes, buildings are something started rather than finished. The notion of permanence in architecture, and the inertia it develops as both an object and a practice may be an obvious challenge to this notion of adaptability, and yet, because some forms of durability are pre-conditions to long-term adaptation, the interplay between degrees of permanence and transformability are at the crux of a path to adaptive resilience. Indeed, a critical framework of social-ecological resilience must engage with questions of architecture over time.

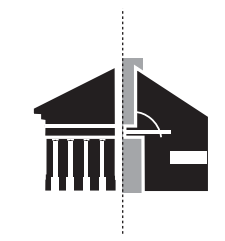

DURABILITY \& TRANSFORMABILITY changing concepts

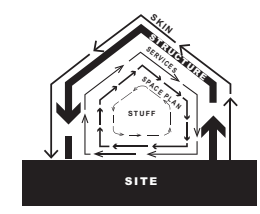

SHEARING LIFE CYCLES changing artifacts

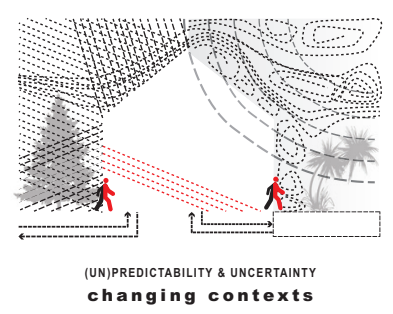

changing coo
Figure 7. Time and Change in Architecture.The disciplinary discourse on architecture and time can be organized according to three forms of change in architecture: (1) The changing cultural concepts, from perceptions to materializations of permanence and ephemerality, which provide a critical theoretical lens to view and organize the relationship between the durable and the transformable aspects of architecture (left); (2) The changing physical artifact of architecture, made of "shearing layers," as Steward Brand described the very different life cycles of building components (center, adapted from Brand); (3) The changing economic, ecological and cultural contexts that define architecture over time. Image by authors.

\section{ARCHITECTURE AND TIME}

The first premise of a framework for social-ecological resilience is the expectation that architecture operates at multiple physical scales and, more importantly, at long time scales requiring the constant adaptation to the changing contexts of technical, organizational, social, and economic domains. Second, such a framework must also recognize that an individual piece of architecture over time is a constantly changing artifact consisting of multiple systems with different life cycles, transformative capacities, and required variability. Third, in considering both a dynamically changing context and a dynamically changing artifact over a long time, a theory for social-ecological resilience in architecture must also acknowledge and learn from the changing concepts of architecture and time. This change demands critical engagement with the idea of permanence traditionally associated with architecture in the western world, of stability and predictability embedded in the many assumptions of the design process, and of temporality and adaptation emerging in the recent discourse. Although social-ecological resilience is a new concept within the discipline of architecture, the themes that emerge suggest that this broad concept can effectively engage and reorganize the extensive and sometimes marginalized discourse that explores changing concepts, changing contexts, and changing artifacts of architecture over time (Figure 7).

\subsection{Changing concepts}

Western traditions before the nineteenth century associated architecture with monumental and permanent artifacts, represented by the perceived durability of solid mass structures (Fergusson 1907). The nineteenth and twentieth centuries saw an intensified quest for lightness emerge with new paradigms about architecture and time (Ford 1997). Reexamining the discourse reveals a recurrent theme on the interplay between science and architecture. Early theoretical works, including Sigfried Giedion's book Space, Time and Architecture, claimed the transformation of thinking in the arts and design culture was generated by new concepts from science (1962). More recently, Sanford Kwinter in Architectures of Time makes this case most explicitly: that the "time problem" or the "demise of absolute time" that transformed spatial thinking and aesthetics in the twentieth century emerged from physics with the theories of relativity, which then gives way to biology as a model of scientific and metaphysical explanation (2001). Kwinter's theory proposes that science brings to design thinking the complexities of systems, replacing the static technical object of architecture with dynamic relations of parts that are both smaller and larger than the traditional object, and suggesting an architecture of active agencies that includes moving, flexible processes. These ideas resonate with socialecological views of changing cross-scale dynamics in space and time, and the facilitation of social agency.

Theories about science also raised important questions about the dangers of assuming complete predictability and control. Alberto Perez Gomez argued that the scientific revolution in the seventeenth and eighteenth century led architecture to adopt a role as a positivist science, in the utopian belief that the discipline could fully understandand therefore control-phenomena through mathematics and science (1983). Perez-Gomez described the era of positivism ending with the 
urban crisis of modernism only a decade after the ecologist C.S. Holling had proposed the term resilience to replace concepts of stability (1973). Architecture has long followed scientific developments, and it seems almost predictable that the science of ecology would eventually emerge to bring the concept of resilience to architecture. Yet the bulk of resilience discourse in building practice still follows a positivist view. ${ }^{6}$ The adaptive resilience framework provides a productive alternative at a time when architecture most urgently needs to embrace uncertainty and relinquish predictability and control.

Similarly, Henry Cowan noted that architectural science followed revolutions in physical sciences and mathematics (1966). The scientific revolutions and related cultural changes described by Giedion, Kwinter and Perez Gomez, are reflected in Cowan's history of architectural science, which he characterizes as transitioning from a quest for permanence and stability in masonry to a quest for lightness and transparency, giving rise to the dominance of environmental design. Enabled by advances in mechanics of materials and thermodynamicsand empowered by positivist views of engineered control in a mechanized environment-architectural science was expected to compensate for the poor environmental performance of the structure and enclosure through the application of energy. Notably, Reyner Benham made the case that early modern architecture still prioritized structural technology over the integration of environmental technology, exalting later works that achieved full control of the environment (1984). Environmental, and particularly energy, considerations eventually prompted the recent focus on the role of the building envelope, and integrated design approaches that rethink the "culture of mechanically controlled internal environments: the manufactured sense of comfort"(Lovell 2010, 60). Others, like Michelle Addington, criticized high-performing envelopes as inadequate compensation for architects' poor material choices and misunderstandings about the human body's mechanisms for thermal comfort (2009). Moreover, complex and highly optimized enclosure and mechanical systems complicate operation, maintenance and replaceability, reducing adaptive capacity. Contemporary discourse on adaptation suggests that artificial intelligence can "translate unrecognized stimuli to recognized stimuli" which are "unanticipated by human and/or organizational capacities" but it also warns of the potential for "maladaptation" beyond the scale of the building, specifically ethical conflicts with urban and ecological goals (Keenan 2014, 25-26). Critically, the ever-greater optimization of building technology increases vulnerabilities and limits adaptability to unpredictable changes in climate and use, driving buildings into obsolescence sooner than desired. Considering that adaptive capacity is dependent on social actors, considerations of technology's effects on user behavior, tendency towards accelerated obsolescence, and ensuing decrease in economic and cultural value, are paramount to build socialecological resilience.

As metaphor, adaptive resilience describes the relationship between the slow moving systems in architecture (morphological and passive

\footnotetext{
${ }^{6}$ As an example, the report from the Resilience Building Coalition is subtitled

"Helping communities construct a more certain future"(2016)
}

systems dictated by site and climate) and the fast moving (technical or active systems dictated by use and culture) in a way that is analogous with the relationship between the slow moving systems in ecology (geological structure) and the dynamic or fast moving systems (biological systems). Louis Kahn proposed an organizational strategy that negotiates the two, making the massive structure a container of the building services emblematic of what he called the order of integration (1955). The notion of served and servant space transformed the slower changing elements of the structure into cavities that channeled the fast-changing components of mechanical systems. Kahn-said to be both fascinated with the natural sciences and inspired by the beauty of ruins-reconsidered the most elemental and enduring aspects of architecture, what remains after a long time, reverting back to the "invincible physicality" of architecture (Scully 1992). For Kahn, the long lasting massive structure creates a permanent order, a framework for the changing life within, and its beauty is defined by the way the mass of the structure mediates light (Larson 2000). While Kahn did not discuss resilience explicitly, his theory and built work manifest these principles, for example, at the Salk Institute where this dialogue between structure and services is still today deemed an extraordinary integration of order, performance, adaptability and beauty (Moe 2008).

The proposition that a building persists through multiple futures or "new normals" suggests that durability and transformability, as opposed to static permanence, are necessary qualities of an architecture that adapts to a changing context. Over time, the configuration of the slow changing elements of architecture contains, supports, organizes and enables the deconstruction and transformation of the more ephemeral and interchangeable components. Thus, what makes architecture worth keeping and adapting is what allows it to persist: the enduring qualities that enable the temporal to flourish.

\subsection{Changing contexts}

Architecture is a contextual and contingent discipline with pragmatic and cultural considerations, functional requirements and serious responsibilities for life safety and health. Architects design based on a number of assumptions: a specific climate, use and occupancy, structural loads, cost, revenue and appreciation, and material availability, among many others. These assumptions rely on predictions which whether based on faith, whims of a patron, scientific models, or analysis of probability and confine the creative process to specific conditions, most often assumed to be either stable or changing at foreseeable rates and magnitudes. Steward Brand asserted: "architects want to control the future;" and noting "a big, physical building seems a perfect way to bind the course of future events;" although he warns "the future is no more controllable than it is predictable" $(1994,181)$. The expectation of predictability and control creates conditions of "path dependence" the sort of self-fulfilling prophecy in which designing for the future helps bring it about. Even the early focus on sustainability centered on "efficiency" and "optimization," suggesting that we may become "locked-in" to modeled conditions. Resilience acknowledges that many of these assumptions will not remain valid for long, that conditions are changing at unpredictable rates and magnitudes and models often fail to predict the complexity of dynamic interactions such as user behavior. Thus, describing the performance of buildings, especially in relation to 
changing material, economic, social, and environmental forces required to construct and sustain them, is a more nuanced approach than efficiency.

On the other hand, architects always imagine and anticipate a different future and work to bring it into being; making decisions that transform space for a long time. Designing for uncertain futures demands a creative process of imagining and planning for many scenarios (Brand 1994). Thus, architects can engage those creative skills to imagine a changing context when designing for resilience. Although designers can anticipate obvious and inevitable changes in every future scenario, the main focus of resilience must be to build adaptive capacity in the face of, and in response to, uncertainty. Often these attempts focus on programmatic flexibility, leading to various conceptual positions about the expression and accommodation of program, such as the specific, the generic, and the alternate (McMorrough 2006). Clearly a highly specific correspondence of architectural form to program risks obsolescence sooner than the expected or useful life of its materials, and is not a good indicator of resilience. Conversely, the generic approach risks stripping architecture of whatever makes it unique and memorable, possibly resulting in structures without cultural value or will to preserve. Furthermore, creating a minimal architecture that necessitates frequent renovation-one governed primarily by consumerist logics of leastfirst cost and maximum rentability-only organized by patterns of mechanical distribution and modularity-promotes short-term thinking and wastes resources, decreasing the broader urban and environmental resilience. John McMorrough (2006) argues that program is and must remain external to architecture, coming before and after the design process to test the essentially architectural. An alternative model of programmatic adaptability based on adaptive resilience would focus on ways the essentially architectural (form, tectonics, materiality, comfort, delight) invites and enables the adaptive reuse of the future. This focus would align with recent efforts to reclaim the importance of purpose (as distinct from program) within architecture (Grabow and Spreckelmeyer 2015).

Recent developments move beyond conversations of programmatic flexibility by proposing adaptability as a typology, one incorporating extension adaptability, internal adaptability and planning adaptability in addition to use adaptability (Cowee 2012). A typological framework of analysis for adaptability suggests that, as described by Moneo (1978), these solutions can be reduced to specific principles of a formal structure that can be repeated. Approaching adaptability through this formal structure relies on the lasting morphological qualities of architecture: orientation on site, connectivity, circulation, daylight, structural pattern, configuration and order. By focusing on specific, persistent criteria, this approach does not depend on optimization to a current use, nor does it need to focus on wasteful excess capacity. Instead, it proposes a strategic approach to design, imagining potential future scenarios, preferring decisions that do not prevent future change and building additional capacity only where necessary to maximize future adaptability. This approach considers the layers of buildings that must be removable and replaceable, minimizing and organizing them to the strictly unavoidable, for example, based on life cycle and expected exposure.
This approach requires reformulating architecture's value in the current economic and cultural environment. According to Michael Benedikt, by 1945 the "architecture of crisis and recovery had become the only game in town," suggesting that since then the built environment has become ever more commodified, subject to short-term investment rather than of "life long dwelling or long-term city making" $(1999,2)$. The reason for this change has been the "relinquishment by architects of their role-indeed duty-in upholding standards and modes of discourses about design that ordinary people can understand and that produce buildings that people want to live and work in for reasons other than the fact that they are new" $(1999,3)$. Wilfred Wang $(2003)$ argues that the willingness to spend more on buildings now to make them durable instead of disposable, the investment of effort now to enable recycling and adaptable reuse of buildings in the future, the ability to see building as valuable and expensive as to not overlook their maintenance, is a cultural problem that necessitates that contemporary culture ceases to see architecture as fashion, as a mere phenomenon for consumption. Such cultural change is the social component of the social-ecological framework, and must start within the discipline of architecture. This view implies that building for resilience is also a necessary instrument of transformation of our cultural context, such that decisions are made based on architecture's lasting qualities, informed by reasonably constructed (albeit uncertain) scenarios.

Many contemporary failures in architecture stem not only from the cultural context but also the changes architecture has been complicit in effecting in the environment. Therefore, design practices must acknowledge that the artifacts produced are responsive to a multiscalar, dynamically changing context, and that such artifacts have immediate transformational power. A resilience view rejects neutral or generic architecture in favor of architecture that creates meaningful, memorable, adaptable and fluid connections with its context. The notions of an architecture that is embedded and actively engaged in its surroundings, the reciprocity between internal and external systems at multiple scales, and a focus on relationships are critical to building resilience, and perhaps best described with the term panarchy.

\subsection{Changing artifacts}

The most obvious but perhaps most overlooked form of change in architecture is the change that inevitably occurs in the artifact over time. Weathering, malfunction, and breakage are natural and expected but are seldom embedded in decision making during the design process and very rarely embedded in regulations except when there is a strong likelihood of impacting life safety (e.g. wind debris protection, fire pump and exhaust fan testing requirements). While the cultural problems raised previously are an obvious culprit, this change is the most notably absent from and marginalized from practice and the academy. Authors like Steward Brand (1994) and William McDonough (2002) have written popular books on sustainability, ecology and design that deal directly with the life cycle of buildings, but are not viewed as central to the discipline. Brand, the author of How Buildings Learn is a critic of modern architecture and a biology-trained media artist interested in extracting ecological principles for human life, and so directed his writing to a non-architectural audience. On the other hand, McDonough, an architect who co-authored Cradle to Cradle, proposes considering full ecological life cycles in buildings (before design/construction and after 
deconstruction), but his book is not explicitly about architecture nor specifically written for an architectural audience. As a result, the ideas in these books, although influential in cultural circles and segments of the profession interested in sustainability, have been absent from or even dismissed by architectural discourse and education. In reconsidering disciplinary boundaries, a critical engagement with resilience in architecture has the potential to reconsider the place of these themes and ideas.

This problem is more clearly reflected in how few practices explore the full life cycle of buildings in ways that transform the production of architecture. A notable exception is the firm of Kieran Timberlake which explored novel systems of construction that carefully planned prefabrication, site assembly and ultimate recycling of components, writing: "As architects, we focus on making, but we should also take responsibility for undoing the things we have made" (Kieran and Timberlake 2008,140). Moreover, much of the recent architectural discourse addressing the life cycle of architectural artifacts has also focused on a critique of practice: the architectural detail of the joint in the envelope of traditional and modern architecture, the virtues and shortcomings of the solid versus layered quality of construction, and the discipline's delegation of considerations about construction, maintenance and operation to builders and consultants. These are important critiques and it is necessary that architectural theory and teaching engage more actively with them, to provide critical context and agency to the current and future curricula and the work in professional practice. For example, Edward Ford (1997) explores the cultural factors that prioritize expediency over long-term durability, and argues that if architects are to be entrusted with the city, engaging a discourse of an architecture of impermanence must result in the architect reclaiming expertise of details to engage with the process of construction. Moreover, Marco Frascari (1996) argues for the detail to not only be a technical problem architects must master, but an essential component of imparting significance and meaning in architecture. Mostavafi and Leatherbarrow (1993) argue that nothing in architecture is permanent, indeed everything is temporary, and invite us to engage critically with the performative and aesthetic implications of, for example the terms weathering and weatherproofing. The first accepts and channels the effect of water, the latter is based on caulks and sealants of such a short lifespan that reveal the term to be an illusion, suggesting an architectural language that embraces the aesthetics of depth and shadow in an articulated façade that more effectively manages the path of water. Their view is also critical of the use of the term organic to refer to things that imitate nature, but instead suggests that architects must anticipate dirt, staining and erosion, and find the beauty in the changes that naturally occur on surfaces. There may appear some tension between design that acknowledges the ravages of time and that which is resilient and enduring. Yet again, finding beauty in the effects of time on buildings simply acknowledges and manages an unavoidable change, and does not preclude an approach to resilience that distinguishes what must change, and what is likely to endure.

\section{CONCLUSION}

Architecture has long aimed at posterity, a tendency perhaps most famously expressed when John Ruskin wrote "...when we build, let us think that we build for ever [sic]. Let it not be for present delight, nor for present use alone; let it be such work as our descendants will thank us for..." (1892, 339). Critically, Ruskin does not call for buildings to last as long as possible: he calls for an approach or attitude that seeks to design buildings worthy of lasting a long time. Ruskin exhorts our thinking, rather than the physical construction to look towards eternity, and this has significant implications for a social-ecological framework of resilience in architecture.

First, and most important, architecture worthy of eternity must conceive of itself outside its immediate time, not by seeking permanence or imposing immutable standards of beauty, but by humbly serving the future. Ruskin envisions not eternal but enduring architecture, buildings that-while satisfying current needs and offering contemporary delights-look toward a future period of human occupancy (1892, 340-41). To do so, resilient architecture must accommodate uncertainty even as it builds in the present, simultaneously contending with which elements are fixed and which are moveable. So while buildings must provide durable shelter, the attribute of endurance is a necessary but not a sufficient condition of resilience. An old building that looked and worked exactly as it did when new holds no interest for Ruskin, hence his vehement disagreements with Viollet-le-Duc about the difference between preservation and restoration of the old, a dispute that we may project forward in conceptualizing resilient architecture.

Second, social-ecological resilience recognizes that buildings exist in dynamic panarchic relationships among technology, human use, and the natural environment. Instead of assuming these relationships will continue as in the present, social-ecological resilience embraces a changing social and ecological context, and the ways building will change with it. Ruskin does not value old buildings simply because of their age, but rather because occupancy over time makes buildings almost like living beings: suggesting human use imparts a gift of "language and of life." (1892, 340-41). Here again we see the importance of resilient architecture open to social and cultural adaptation in the future.

Finally, the physical manifestations of a resilient architecture must be characterized by change over time. Ruskin acknowledges an aesthetic manifestation of the visible effects of time in his appreciation for the picturesque, noting "...we have been speaking of the sentiment of age only, there is an actual beauty in the marks of it." $(1892,341)$. However, he takes pains to emphasize it is not the artificial creation of the symptoms of age, nor the age itself, but rather the relationship with the natural environment of the wear and signs of time that he values. It is the contrast between the enduring building and the transitional character of people and the ever-changing world that imbues the resilient building with character and meaning. To Ruskin, buildings are valuable precisely because events and history affect them, imparting what he calls "the golden stain of time." $(1892,340)$. 
This essay presented competing conceptual frameworks from the literature of resilience external to architecture, including engineering, ecological, and social-ecological models, and considered their implications for architecture. We argued that the social-ecological or adaptive model best engages architecture's richness and complexity of connections with domains of urban resilience at multiple scales, because it includes questions of culture, judgment, learning and intentionality as critical components to absorbing change and adapting over time. A critical review of the discourse shows that architectural theory has been grappling-although sometimes marginally-with ideas about permanence and change in architecture over time. A review of these changing ideas suggests that a framework for social-ecological resilience is critical to transform the education and practice of architecture such that the future generations may find ways to own and occupy, to use and glory in it, to produce, in Ruskin's words, "such work as our descendants will thank us for..." $(1892,339)$.

\section{REFERENCES}

Addington, Michelle. 2009. "Converging Behaviours." In Energies : New Material Boundaries, edited by Sean Lally. Architectural Design ; v. 79, No. 3; Architectural Design (London, England : 1971) ; v. 79, No. 3. Hoboken, N.J. : Wiley.

Almufti, Ibrahim, and Michael Willford. 2013. "REDi Rating System." Arup. http://publications.arup.com/publications/r/redi_rating_system.

Banham, Reyner. 1984. The Architecture of the Well-Tempered Environment. 2nd ed. Chicago : University of Chicago Press.

Benedikt, Michael. 1999. "Less for Less Yet: On Architecture's Value in the Marketplace." Harvard Design Magazine.

Berkes, Fikret. 2007. "Understanding Uncertainty and Reducing Vulnerability: Lessons from Resilience Thinking." Natural Hazards 41 (2): 283-95. https://doi.org/10.1007/s11069-006-9036-7

Blewitt, John, and Daniella Tilbury. 2013. "Resilience in Theory and Practice." In Searching for Resilience in Sustainable Develoment. Florence, KY, USA: Taylor and Francis. http://site.ebrary.com/lib/ northeastern/docDetail.action?docID=10747244.

Brand, Fridolin Simon and Kurt Jax. 2007. "Focusing the Meaning(s) of Resilience: Resilience as a Descriptive Concept and a Boundary Object." Ecology and Society 12 (1): 23. https://doi.org/10.5751/ES-02029120123

Brand, Stewart. 1994. How Buildings Learn: What Happens After They're Built. First Edition edition. New York, NY: Viking Adult.

Bruneau, Michel, Stephanie E. Chang, Ronald T. Eguchi, George C. Lee, Thomas D. O'Rourke, Andrei M. Reinhorn, Masanobu Shinozuka, Kathleen Tierney, William A. Wallace, and Detlof von Winterfeldt. 2003. "A Framework to Quantitatively Assess and Enhance the Seismic Resilience of Communities." Earthquake Spectra 19 (4): 733-52. https://doi.org/10.1193/1.1623497

“Building Rating Systems - USRC." 2016. Accessed June 27. http://usrc. org/building-rating-system.

Carrington, Damian. 2016. "The Anthropocene Epoch: Scientists Declare Dawn of Human-Influenced Age." The Guardian, August 29. https://www.theguardian.com/environment/2016/aug/29/declareanthropocene-epoch-experts-urge-geological-congress-human-impactearth.
Chapman-Henderson, Leslie, and Audrey K. Rierson. 2015. "Disaster Resilience Rising Means the Time Is Right." Disaster Resilience Rising Means the Time is Right Federal Alliance for Safe Homes (FLASH). http://www.flash.org/disasterresiliencerising.pdf.

Chen, Chaomei. 2006. "CiteSpace II: Detecting and Visualizing Emerging Trends and Transient Patterns in Scientific Literature." Journal of the American Society for Information Science and Technology 57 (3): 35977. https://doi.org/10.1002/asi.20317

Cowan, Henry J. 1966. An Historical Outline of Architectural Science. Architectural Science Series; Architectural Science Series. Amsterdam: Elsevier Pub. Co.

Cowee, Natalie Plagaro. 2012. The Typology of Adaptability in Building Construction. Lucerne School of Engineering \& Architecture, Competence Centre for Typology \& Planning in Architecture (CCTP) ; 1. Zürich : VDF Hochschulverlag.

Crutzen, Paul, and Veerabhadran Ramanathan. 2000. "The Ascent of Atmospheric Sciences." Science 290 (5490): 299-304. https://doi. org/10.1126/science.290.5490.299

PMid:17734112

Executive Office of the President, Council on Environmental Quality. 2015. "Fact Sheet: Actions to Build Resilience to Climate Change Impacts in Vulnerable Communities." The White House. https:// www.whitehouse.gov/administration/eop/ceq/Press_Releases/ July_09_2015.

Fergusson, James. 1907. A History of Architecture in All Countries. New York: Dodd, Mead and company.

Folke, Carl. 2006. "Resilience: The Emergence of a Perspective for Social-ecological Systems Analyses." Global Environmental Change, Resilience, Vulnerability, and Adaptation: A Cross-Cutting Theme of the International Human Dimensions Programme on Global Environmental Change, 16 (3): 253-67. https://doi.org/10.1016/j. gloenvcha.2006.04.002

Ford, Edward. 1997. "The Theory and Practice of Impermanence: The Illusion of Durability." Harvard Design Magazine, no. 3.

"Framework for Resilience." 2016. aiab106184. THE AMERICAN INSTITUTE OF ARCHITECTS: Sustainability Initiative. Accessed June 30.

Frascari, Marco. 1996. "The Tell-the-Tale Detail." In Theorizing a New Agenda for Architecture : An Anthology of Architectural Theory, 19651995. New York: New York : Princeton Architectural Press.

Giedion, S. (Sigfried). 1962. Space, Time, and Architecture. Cambridge: Cambridge, Harvard University Press.

Google. 2016. Google Books Ngram Viewer. Accessed June 24. http:// books.google.com/ngrams.

Grabow, Stephen, and Kent F. Spreckelmeyer. 2015. The Architecture of Use : Aesthetics and Function in Architectural Design. New York : Routledge,.

Gunderson, Lance H. 2000. "Ecological Resilience-In Theory and Application." Annual Review of Ecology and Systematics 31 (1): 425-39. https://doi.org/10.1146/annurev.ecolsys.31.1.425.

Holling. 1996. "Engineering Resilience Versus Ecological Resilience." In Engineering within Ecological Constraints, 31-44. Ecological Constraints. Washington, D.C.: Washington, D.C. : National Academy Press. 
Holling, C. S. 1973. "Resilience and Stability of Ecological Systems." Annual Review of Ecology and Systematics 4 (January): 1-23. https:// doi.org/10.1146/annurev.es.04.110173.000245

Hosseini, Seyedmohsen, Kash Barker, and Jose E. Ramirez-Marquez. 2016. "A Review of Definitions and Measures of System Resilience." Reliability Engineering \& System Safety 145 (January): 47-61. https:// doi.org/10.1016/j.ress.2015.08.006

Insurance Institute for Business and Home Safety. 2016. "Fortified Home." https://disastersafety.org/fortified/fortified-home/.

Kahn, Louis I. 1955. "Order and Form." Perspecta 3: 47-63. https://doi. org/10.2307/1566835

Kaplan, Stanley, and B. John Garrick. 1981. "On The Quantitative Definition of Risk." Risk Analysis 1 (1): 11-27. https://doi. org/10.1111/j.1539-6924.1981.tb01350.x

Keenan, Jesse M. 2014. "Material and Social Construction: A Framework for the Adaptation of Buildings." Enquiry : The ARCC Journal of Architectural Research 11 (1).

Kennedy, Jim, Joseph Ashmore, Elizabeth Babister, and Ilan Kelman. 2008. "The Meaning of 'Build Back Better': Evidence From PostTsunami Aceh and Sri Lanka." Journal of Contingencies and Crisis Management 16 (1): 24-36. https://doi.org/10.1111/j.14685973.2008.00529.x Kijewski-Correa, Tracy, and Alexandros A. Taflanidis. 2011. "The Haitian Housing Dilemma: Can Sustainability and HazardResilience Be Achieved?" Bulletin of Earthquake Engineering 10 (3): 765-71. https://doi.org/10.1007/s10518-011-9330-y

Kieran, Stephen, and James Timberlake. 2008. Loblolly House Elements of a New Architecture. New York: New York : Princeton Architectural Press.

Kwinter, Sanford. 2001. Architectures of Time : Toward a Theory of the Event in Modernist Culture. Cambridge, MA: Cambridge, MA : MIT Press.

Laboy, Michelle, and David Fannon. 2015. "Learning Comprehensive Building Design through a Resilience Framework." In Proceedings. Sheffield, UK: Sheffield School of Architecture.

Larson, Kent. 2000. Louis I. Kahn : Unbuilt Masterworks. Kahn. New York, NY: New York, NY : Monacelli Press.

"LEED Credit Library | U.S. Green Building Council." 2016. Accessed June 30. http://www.usgbc.org/credits/new-construction/v4/pilotcredits?keys=Resilience.

Lewis, James. 2003. "Housing Construction in Earthquake-Prone Places: Perspectives, Priorities and Projections for Development." Australian Journal of Emergency Management, The 18 (2): 35.

Lovell, Jenny. 2010. Building Envelopes : An Integrated Approach. New York: New York : Princeton Architectural Press.

Luthar, Suniya S., Dante Cicchetti, and Bronwyn Becker. 2000.

"The Construct of Resilience: A Critical Evaluation and Guidelines

for Future Work." Child Development 71 (3): 543-62. https://doi. org/10.1111/1467-8624.00164

PMid:10953923 PMCid:PMC1885202

Lyons, Michal. 2009. "Building Back Better: The Large-Scale Impact of Small-Scale Approaches to Reconstruction." World Development 37 (2): 385-98. https://doi.org/10.1016/j.worlddev.2008.01.006
Mannakkara, Sandeeka, and Suzanne Wilkinson. 2014. "ReConceptualising 'Building Back Better' to Improve Post-Disaster Recovery." International Journal of Managing Projects in Business 7 (3): 327-41. https://doi.org/10.1108/IJMPB-10-2013-0054

McMorrough, John. 2006. "Notes on the Adaptive Reuse of Program." Edited by Amanda Reeser Lawrence and Ashley Schafer. Re:programming, Praxis : journal of writing + building, , no. 8.

Minnery, Rachel, and FAIA. 2015. "Resilience to Adaptation." Architect. August 4. http://www.architectmagazine.com/aia-architect/aiafeature/ resilience-to-adaptation_o.

Mitchell, James. 1999. Crucibles of Hazard: Mega-Cities and Disasters in Transition. United Nations University Press. http://lib. riskreductionafrica.org/handle/123456789/297.

"Mitigation Assessment Team Program | FEMA.gov." 2016. Accessed June 30. https://www.fema.gov/mitigation-assessment-team-program.

Moe, Kiel. 2008. "Extraordinary Performances at the Salk Institute for Biological Studies." Journal of Architectural Education 61 (4): 17-24. https://doi.org/10.1111/j.1531-314X.2008.00183.x

Moneo, Rafael. 1978. "On Typology." Oppositions : A Journal for Ideas and Criticism in Architecture 13: 22-45.

Mostafavi, Mohsen. 1993. On Weathering: The Life of Buildings in Time. Cambridge, Mass.: Cambridge, Mass. : MIT Press.

"My Safe Florida Home Hurricane Inspection Info." 2016. Accessed June 27. http://mysafeflorida.org/mysafefloridahome.html.

Obama, Barack. 2013. "Executive Order 13514: Preparing the United States for the Impacts of Climate Change." Code of Federal Regulations. https://www.whitehouse.gov/the-press-office/2013/11/01/executiveorder-preparing-united-states-impacts-climate-change.

Obama, Barack. 2013. "Presidential Policy Directive -- Critical Infrastructure Security and Resilience." Office of the Press Secretary. https://www.whitehouse.gov/the-press-office/2013/02/12/ presidential-policy-directive-critical-infrastructure-security-and-resil. Pendall, Rolf, Kathryn A. Foster, and Margaret Cowell. 2010. "Resilience and Regions: Building Understanding of the Metaphor." Cambridge Journal of Regions, Economy and Society 3 (1): 71-84. https://doi. org/10.1093/cjres/rsp028

Pérez Gómez, Alberto. 1983. Architecture and the Crisis of Modern Science. Cambridge, Mass.: Cambridge, Mass. : MIT Press.

"Rebuild by Design." www.rebuildbydesign.org.

"Resilience." 2016. Dictionary.com Unabridged. Random House, Inc. Accessed June 28. http://www.dictionary.com/browse/resilience.

"Resilience - The American Institute of Architects." 2016. Accessed June 30. http://www.aia.org/practicing/resilience/index.htm.

Resilience Building Coalition. 2016. "Preparing To Thrive: The Building Industry Statement on Resilience." http://c.ymcdn.com/sites/www. nibs.org/resource/resmgr/Docs/WHRS_SignatoryReport_final.pdf.

"Resilient Design Guide: High Wind Wood-Frame Construction Edition." 2015. FLASH.

“Resilient Design Strategies." 2016. Resilient Design Institute. Accessed June 30. http://www.resilientdesign.org/resilient-design-strategies/.

"ResilientCity | Resilient Design Principles." 2016. Accessed June 30. http://www.resilientcity.org/index.cfm?ID=11900. 
"Resilient Design Strategies." 2016. Resilient Design Institute. Accessed June 30. http://www.resilientdesign.org/resilient-design-strategies/.

Rockefeller Foundation. 2016. "100 Resilient Cities.” Accessed June 28. www.100resilientcities.org.

Ruskin, John. 1892. The Seven Lamps of Architecture. Brantwood ed. New York: C. E. Merrill \& Co.

Scheffer, M., S.H. Hosper, M-L. Meijer, B. Moss, and E. Jeppesen. 1993. "Alternative Equilibria in Shallow Lakes." Trends in Ecology \& Evolution 8 (8): 275-79. https://doi.org/10.1016/0169-5347(93)90254-M

Scully, Vincent. 1992. "Louis I. Kahn and the Ruins of Rome." MoMA, no. 12: 1-13.

Tierney, Kathleen J., and Michel Bruneau. 2007. Conceptualizing and Measuring Resilience: A Key to Disaster Loss Reduction. Emmitsburg, MD: National Emergency Training Center.

"Understanding Resilience." 2016. aiab107411. THE AMERICAN INSTITUTE OF ARCHITECTS: Sustainability Initiative. Accessed June 30. http://www.aia.org/aiaucmp/groups/aia/documents/pdf/aiab107411. pdf.

Walker, Brian, C. S. Holling, Stephen R. Carpenter, and Ann P. Kinzig. 2004. "Resilience, Adaptability and Transformability in Social-Ecological Systems." Ecology and Society 9 (2). http://www.ecologyandsociety. org/vol9/iss2/art5/.

Walker, Brian, and David Salt. 2012. Resilience Thinking : Sustaining Ecosystems and People in a Changing World. Washington, US: Island Press. http://site.ebrary.com/lib/alltitles/docDetail. action?docID=10729958.

Wang, Wilfred. 2003. "Sustainability Is a Cultural Problem." Harvard Design Magazine, no. 18 (Spring/Summer).

WBDG Secure/Safe Committee. 2016. "Natural Hazards Mitigation." Whole Building Design Guide. Accessed June 30. https://www.wbdg. org/design/resist_hazards.php.

White House Conference on Resilient Building Codes. 2016. White House. https://www.whitehouse.gov/the-press-office/2016/05/10/ fact-sheet-obama-administration-announces-public-and-private-sector.

Wu, Jianguo, and Tong Wu. 2013. "Ecological Resilience as a Foundation for Urban Design and Sustainability." In Resilience in Ecology and Urban Design: Linking Theory and Practice for Sustainable Cities, 2013 edition, 211-30. Dordrecht; New York: Springer. https://doi.org/10.1007/978-

94-007-5341-9_10 